\title{
THE FREQUENCY OF TUBERCULOSIS IN CHILDHOOD*
}

\author{
FRANZ HAMBURGER \\ Professor of Pediatrics, University of Graz \\ STYRIA, AUSTRIA
}

In collaboration with Monti, ${ }^{1}$ I found that 95 per cent. of the children of the poor in Vienna showed evidence of a tuberculous infection at the time of puberty. Since then a number of papers on this subject have appeared from various cities and countries. The results were very different. The cause of this variation lies partly in the actual differences in the various cities, but to a certain extent the difference in the method used for the examination and the difference in the selection of the material share the responsibility.

I regard it necessary that the important question of the spread of tuberculosis in definite cities, countries and strata of society should be answered definitely. To this end it is absolutely necessary to use the best methods of examination and to select the material properly.

\section{SELECTION OF MATERIAL}

A true picture of the actual conditions can only be obtained by examining either all children of a certain age, or all children, which is hardly possible. The examination of school children means a selection which can be regarded as free from objection and so does the examination of children attending public kindergartens. The examination of children in infectious disease hospitals can also be used because it is permissible to assume that children with or without tuberculosis acquire diphtheria or scarlet fever with equal readiness. Figures obtained in a scarlet fever or diphtheria ward surely may be regarded as representative of the actual conditions, but it is not permissible to use results obtained in a dispensary for the preparation of statistics. This material includes many more tuberculous children than the average. Tuberculous children tend to concentrate there and the figures become too high. For this reason the figures which Von Pirquet gave in his first statistic based as they were on the material of the dispensary of the Vienna Kinder Klinik cannot be accepted; and many contributions of other investigators share this fate.

\section{TUBERCULIN METHOD}

It is not sufficient to exercise proper care in the selection of the material but the tests have to be made with a reliable method. Only

* Received for publication, March 18, 1922.

1. Hamburger and Monti: München. med Wchnschr. 56:450, 1909. Monti: Wien. med. Wchnschr. 62:447, 1912; Wien. klin. Wchnschr. 21:1407, 1908. 
then can the frequency of tuberculosis be established. The justification of such a demand is self-evident. Nobody will doubt its principle in the least. In spite of this many papers dealing with the frequency of tuberculosis in different cities and countries reveal the fact that, quite generally, a tuberculin method has been used which is entirely unreliable, having an error as high as 40 per cent. This method is the cutaneous tuberculin test of Pirquet. The main purpose of this paper is to call attention to the fact that this method is inexact and therefore misleading. It gives figures which are far too low.

The method of Pirquet is very simple. It rapidly gained great favor and was used widely. Many papers are published which are based entirely on the Pirquet method, but the results are wrong because the method is inexact. Twelve years ago, Reuschel, ${ }^{2}$ and shortly afterward I, called attention ${ }^{3}$ to this fact. It was shown that the local subcutaneous reaction (so-called Stichreaction) gives much more reliable results. I have called attention again and again to this unreliablity of the Pirquet reaction and particularly in my monograph on tuberculosis in childhood, but, I regret to say, without much success.

A comparison of the figures obtained by Pirquet with his cutaneous method with those obtained by Monti and myself with the local subcutaneous method demonstrates the degree of error of the cutaneous reaction. Vienna furnished the material for both statistics. Pirquet found in children from 11 to 14 years of age an incidence of tuberculosis of only 56 per cent.; we found 95 per cent., i. e., 40 per cent. more. At that our figures were obtained from a material (hospital for infectious diseases) in which rather less tuberculous infection was to be expected than in the material of Pirquet (dispensary). Only very few authors confirmed the statements of Reuschel and myself (Nothmann,, Pirquet, ${ }^{5}$ Rominger ${ }^{6}$ ). Occasionally the intracutaneous method of Mantoux has been employed, but not frequently. This method has no advantages over the subcutaneous method and at times the dosage remained insufficient. In order to exclude tuberculosis, the reaction must remain negative with from 1 to $10 \mathrm{mg}$.

The method I worked out in detail is this: All children to be examined are first subjected to a cutaneous or percutaneous test with concentrated tuberculin. ${ }^{7}$ Those who do not react, from twenty-four to forty-eight hours later, receive a subcutaneous injection of $0.01 \mathrm{mg}$.

2. Reuschel: München. med. Wchnschr. 55:330, 377, 1908.

3. Hamburger: Wien. klin. Wchnschr. 21:381, 1908.

4. Nothmann: Berl. klin. Wchnschr., 1910, No. 9.

5. Pirquet: Ergebn. d. inn. Med. u. Kinderh. 5:

6. Rominger: Monatschr. f. Kinderh. 18:424, 1920.

7. With the percutaneous inunction method of Moro more positive results are obtained if the original tuberculin is evaporated on the waterbath ad maximum (F. Hamburger and F. Stradner: München. med. Wchnschr. 45:243 [Feb. 27] 1919). 
tuberculin. Those who do not react after the second injection are given a third injection after a further twenty-four hours. If the test is negative, another injection is given after the lapse of another twentyfour hours, or at most forty-eight hours, the dosage being raised to $1 \mathrm{mg}$. If the place of injection does not show any reaction, such as definite redness and infiltration, the child may be regarded as free from tuberculosis with nearly absolute certainty. In doubtful cases, an injection of $10 \mathrm{mg}$. is given.

It is evident that this method is time consuming and bothersome. In schools and similar public institutions it meets with opposition. The cutaneous or percutaneous method, on the other hand, is very simple in its execution and does not meet with opposition. A cumbersome method of examination competes with a simple one, but the cutaneous method is absolutely unreliable and the subcutaneous method is reliable. It cannot be the object of scientific investigation to find out how many individuals of a given age give a positive cutaneous reaction, but solely how many children of a given age are infected with tuberculosis. The cutaneous method cannot be used comparatively on the assumption that the percentage of its error remains constant. The results of this method are too dependent on a variety of circumstances: (1) The kind of instruments used (Pirquet's "Bohrer," scalpel, vaccination lancet, needle) and the depth of the wound. (2) The length of time the tuberculin acts. (3) The activity of the tuberculin. The different series of the same firm have by no means a constant activity. (4) Whether the cutaneous test has been made once or repeatedly. In the latter case more positive results are obtained. (5) The time of the year seems to exercise some influence on the reaction. ${ }^{8}$

Sufficient data, I believe, have been given to show that the cutaneous reaction cannot alone be used to determine the frequency of tuberculosis. The cutaneous or percutaneous method should be employed first and only when these reactions are negative the subcutaneous method just described should be used.

\section{SUM MARY}

To determine the frequency with which tuberculous infection has occurred in various periods of childhood, it is necessary (1) to select properly the material to be examined. The test can be done in children from schools or kindergartens or from infectious disease hospitals, but not in children from dispensaries. (2) To choose the proper method of applying the tuberculin test. The only suitable method is the subcutaneous injection (from 1 to $10 \mathrm{mg}$.) after a preceding cutaneous or percutaneous application. The cutaneous or percutaneous method alone cannot be used.

8. Hamburger: München. med. Wchnschr. 67:398, 1920. 